\title{
Comunidade de remanescentes de quilombolas: práticas culturais de cuidado utilizadas no puerpério
}

\author{
A quilombola remnants community: cultural health care practices used in puerperium \\ Comunidad de remanentes quilombolas: prácticas cultual de atención utilizadas en el puerperio
}

\author{
Tâmara Silva de Lucenal'® ; Luana Jeniffer Souza Farias da Costa' ${ }^{\circledR}$; \\ Amuzza Aylla Pereira dos Santos ' ${ }^{0}$; Jovânia Marques de Oliveira e Silva '®
}

'Universidade Federal de Alagoas, Maceió, AL, Brasil

\begin{abstract}
RESUMO
Objetivo: descrever as práticas culturais de cuidado no puerpério de mulheres quilombolas. Método: estudo descritivo, de abordagem qualitativa e delineado por meio da Teoria da Diversidade e Universalidade do Cuidado de Madeleine Leininger. Participaram do estudo quatorze mulheres quilombolas que já tinham vivenciado o período puerperal. A coleta das informações ocorreu de junho a setembro de 2018. Projeto aprovado por Comitê de Ética em Pesquisa. Resultados: observou-se a manutenção das crenças e valores, considerando a cultura local relacionada às práticas de cuidado de puérperas quilombolas. Considerações finais: as práticas de cuidado desenvolvidas por mulheres quilombolas no pós-parto se caracterizam por receber influência das crenças, valores e modos de vida que foram transmitidas por meio da oralidade por outras mulheres que já tinham vivenciado esse período.

Descritores: Mulheres; Período Pós-Parto; Enfermagem; Grupo com Ancestrais do Continente Africano.
\end{abstract}

\begin{abstract}
Objective: to describe cultural practices of health care for quilombola women in puerperium. Method: this qualitative, descriptive study was framed by Madeleine Leininger's Theory of Culture Care Diversity and Universality. Fourteen quilombola women who had already experienced the puerperal period participated in the study. Information was collected from June to September 2018. The project was approved by the research ethics committee. Results: beliefs and values were observed to be maintained in the local culture as regards practices of care for puerperal quilombola women. Final considerations: the postpartum care practices applied by quilombola women were characteristically influenced by the beliefs, values and ways of life transmitted orally by other women who had already experienced puerperium.

Descriptors: Women; Postpartum Period; Nursing; African Continental Ancestry Group.
\end{abstract}

\section{RESUMEN}

Objetivo: describir las prácticas culturales de atención a la salud de las mujeres quilombolas en el puerperio. Método: este estudio cualitativo y descriptivo fue enmarcado por la Teoría de la Cultura Cuidado de la Diversidad y Universalidad de Madeleine Leininger. Participaron del estudio catorce mujeres quilombolas que ya habían pasado por el puerperio. La información se recopiló de junio a septiembre de 2018. El proyecto fue aprobado por el comité de ética en investigación. Resultados: se observó el mantenimiento de creencias y valores en la cultura local en cuanto a prácticas de cuidado de las puérperas quilombolas. Consideraciones finales: las prácticas de atención posparto aplicadas por las mujeres quilombolas estuvieron característicamente influenciadas por las creencias, valores y formas de vida transmitidas oralmente por otras mujeres que ya habían experimentado el puerperio.

Descriptores: Mujeres; Periodo Posparto; Enfermería; Grupo de Ascendencia Continental Africana.

\section{INTRODUÇÃO}

O puerpério é popularmente conhecido como quarentena, dieta ou resguardo, de acordo com os aspectos socioculturais ${ }^{1}$. É caracterizado por ser uma etapa marcante na vida da mulher, permeada por modificações locais e sistêmicas, provenientes da gravidez e do parto. Inicia-se com a dequitação placentária, mas seu fim ainda é pouco definido, apesar de, geralmente, estar estabelecido entre seis e oito semanas, quando o corpo começa a retornar ao seu estado pré-gravídico².

Devido a essas modificações, a mulher no período pós-parto necessita de apoio emocional e auxílio nas suas atividades diárias, provenientes tanto da sua rede pessoal como dos profissionais de saúde. Todavia, a forma como esse auxílio será ofertado irá depender da cultura e do momento que está sendo vivenciado. Desse modo, os cuidados demandados no puerpério não dependem apenas dos profissionais, mas também daqueles oriundos da rede sociocultural da mulher ${ }^{3}$. 
Por conta desses cuidados advindos da prática familiar, as orientações fornecidas pelos profissionais de saúde podem se contrapor ao conhecimento popular e não serem realizadas pela puérpera, uma vez que as relações familiares influenciam na maneira que o indivíduo percebe e vivencia o processo saúde-doença, bem como nas necessidades de cuidado com seus membros, momento em que a família tende a ser o suporte e o apoio ${ }^{4,5}$.

Durante o puerpério, existem muitas práticas culturais que estão enraizadas na sociedade atual relacionadas a higiene corporal, alimentação, atividade sexual, atividade física, aleitamento materno e cuidados com a ferida operatória, sendo a família um importante propagador dessas práticas cotidianas, uma vez que há a valorização de experiências. Os significados, os padrões e as modalidades de cuidado são culturalmente adquiridos, de acordo com Leininger ${ }^{6,7}$

De forma mais específica, as práticas de cuidados desenvolvidas por puérperas são desconhecidas para muitos profissionais, acentuando-se tal desconhecimento quando trazidas para o contexto das comunidades quilombolas, cuja dificuldade de acesso à assistência se eleva por conta da localização, ratificando a complexidade e a gravidade das condições de saúde e educação dessa população. Esses fatos reforçam que a situação de vulnerabilidade ainda persiste nesse grupo, devido ao seu processo histórico e cultural, o que ocasiona desigualdades sociais, bem como menor acesso a bens e serviços ${ }^{8,9}$.

Ao relacionar o cuidado com o período puerperal, torna-se fundamental conhecer as experiências das mulheres durante esse lapso temporal para que o cuidado prestado seja singular e coerente com as suas demandas ${ }^{10}$. O puerpério é caracterizado como um dos momentos mais importantes da vida feminina, mas nem sempre as mulheres experienciam esse momento de forma semelhante, uma vez que o mesmo é influenciado por várias formas de cuidado e guiado pelo conhecimento empírico, repassado de geração em geração, a depender do contexto de cada mulher ${ }^{10}$.

Para além do biológico/fisiológico, o período puerperal também é permeado por modificações psicológicas e emocionais. Corresponde a um momento de delicadeza, não apenas pela mudança de papéis da mulher-mãe, mas também pela oscilação de sentimentos, marcada pela euforia, medo, alívio e ansiedade, os quais são desencadeados e influenciados pelas alterações hormonais e pelas novas exigências geradas no tornar-se mãe ${ }^{11}$.

Logo, é preciso conhecer o contexto das mulheres no puerpério, suas crenças, práticas e valores para que, então, o profissional de saúde possa prestar um cuidado culturalmente congruente ${ }^{13 .}$ Desse modo, as relações familiares influenciam na maneira que o indivíduo percebe e vivencia o processo saúde-doença, bem como nas necessidades de cuidado com seus membros, tendo em vista que o apoio e o suporte familiares são fundamentais ${ }^{4,5}$

Nesse sentido, este estudo objetivou descrever as práticas culturais de cuidado no puerpério de mulheres quilombolas.

\section{MÉTODO}

Estudo descritivo, de abordagem qualitativa e delineado por meio da Teoria da Diversidade e Universalidade do Cuidado de Madeleine Leininger ${ }^{12}$. A pesquisa foi realizada na Comunidade de Remanescentes de Quilombolas do Muquém, situada na cidade de União dos Palmares, no interior de Alagoas. A referida comunidade obteve sua certificação, no ano de 2005, emitida pela Fundação Cultural dos Palmares.

Foram incluídas na pesquisa aquelas mulheres que já tinham vivenciado o período puerperal e que nasceram na Comunidade de Remanescentes de Quilombolas do Muquém. Como critério de exclusão possuir incapacidade cognitiva que impossibilite a comunicação. A aproximação com as participantes da pesquisa ocorreu por meio de atividades educativas desenvolvidas pela pesquisadora na comunidade. Após isso, identificou-se as participantes do estudo e, tendo como base os critérios de inclusão da pesquisa, houve a visitação das mulheres pela pesquisadora. Foram-lhes apresentados os objetivos do estudo e logo após a explicação foi realizado os convites para participação no estudo. Todas aceitaram participar do estudo, não havendo recursas. Assim as entrevistas foram agendadas com horário e local, de acordo com a disponibilidade de cada mulher para realizar a entrevista.

A coleta das informações se deu por meio de entrevista semiestruturada, no período de junho a setembro de 2018, com a imersão da pesquisadora no campo. Para tanto, utilizou-se um gravador de voz. Após esta etapa as entrevistas foram transcritas na íntegra com posterior análise. A realização das transcrições se deu de forma fidedigna à narrativa com a preservação das identidades das mulheres, utilizando-se um pseudônimo para substituir o nome.

A análise das informações ocorreu por meio do método sistemático da pesquisa qualitativa, seguindo as etapas de pré-análise, exploração do material, tratamento dos dados, inferência e interpretação, emergindo, a partir daí, três unidades de significância. As unidades foram amparadas pela Teoria de Leininger, no qual pode-se assimilar a universalidade e diversidade do cuidado, proposto pela Teórica. A averiguação das etapas se deu por meio do checklist Consolidated Criteria for Reporting Qualitative Research (COREQ). A pesquisa foi aprovada sob o Parecer $n=2.725 .381$, 
do Comitê de Ética em Pesquisa, obedecendo às normas previstas nas Resoluções no 466/12 e no 510/2016, ambas do Ministério da Saúde.

\section{RESULTADOS}

Participaram deste estudo quatorze mulheres que vivenciaram o puerpério na Comunidade de Remanescentes de Quilombolas do Muquém. Observou-se a manutenção dos costumes e tradições, considerando a cultura local relacionada às práticas de cuidado de puérperas quilombolas. Após leitura e análise das entrevistas, foram construídas as unidades de significância: Práticas de cuidado relacionadas ao repouso, práticas de cuidado relacionadas à higiene, práticas de cuidado relacionadas à alimentação

\section{Práticas de cuidado relacionadas ao repouso}

O cuidado recebido durante o puerpério é envolvido por crenças, valores e práticas que são transmitidas de geração em geração. $O$ repouso no período puerperal é realizado a fim de evitar complicações para preservar a saúde no pós-parto. Assim, a mulher se priva das atividades habituais, dentre elas a atividade doméstica, como meio de evitar problemas de saúde no futuro, conforme demonstram as falas a seguir:

\section{A gente só pegava a vassoura com 30 dias. (Tangela)}

Ah minha filha, ninguém pegava numa vassoura, só quando inteirasse um mês era que pegava numa vassoura para varrer uma casa. (Tisha)

Nada de se abaixar, varrer a casa era só pelo meio! Ela me dizia que não podia pegar peso. Ela me dizia que essas partes da gente "fica" aberta (aponta para a região pélvica) e só "voltava" ao normal depois de 45 dias. (Latasha)

E depois de um mês e quinze dias eu tomava conta do serviço (Gina)

É possível observar, na fala de Latasha, que o cuidado exercido por ela no puerpério é proveniente da cultura que Ihe foi transmitida. Essa prática de cuidado exercida advém de gerações anteriores, mantendo a cultura na comunidade. A universalidade do cuidado se apresenta para as mulheres do estudo, uma vez que todas elas exercem o repouso dos serviços domésticos, evitando pegar peso, pois para elas o corpo está “aberto", ou seja, está exposto a doenças.

Para as mulheres entrevistadas, o retorno à atividade sexual tem um período previsto, guardando repouso de pelo menos trinta dias após o parto, como descrito nas falas:

Relação com o marido só depois de 45 dias... A minha sogra me dizia, que se a pessoa quer ter saúde só era para procurar o marido depois dos 45 dias. (Latasha)

No resguardo, o cuidado eu dizia para o meu marido: vamos separar um pouquinho, aí ficava longe dele uns três meses e depois se juntava de novo! (Maisha)

O resguardo terminou com 30 dias, mas espere mais 15 dias para você se entregar pro seu marido, a minha tia dizia. (Malayka)

Outro tema abordado pelas entrevistadas, retratado como complicação proveniente do não repouso, é a hemorragia pós-parto, conforme referenciado pelas mulheres:

A minha mãe dizia para não fazer esforço. Para não pegar peso né? Não sangrar, não ter hemorragia, o cuidado da gente era esse. (Tangela)

As parteiras me ensinavam, as vizinhas... me ensinavam a não pegar peso, não subir ladeira, não sentar de mal jeito...elas diziam essas coisas para não se desmantelar, por causa da mãe do corpo... Para quando chegar a idade não ficar sentindo alguma coisa, devido ao resguardo mal feito... eu hoje tenho saúde por que tive um resguardo bem feito, não fazia essas coisas... A mãe do corpo não é uma bola assim, grande aqui? (aponta para a região do baixo ventre).Toda mulher tem, se ela fizer alguma coisa de mal jeito ela sai para fora, por que o corpo tá aberto. (Etana)

Para Etana, a "mãe do corpo" é considerada uma parte do corpo, sagrada, da mulher, que é responsável por todo componente do corpo feminino, entendendo que, no puerpério, é preciso se resguardar como uma forma de proteção ao eixo feminino, pois se a "mãe do corpo" não estiver bem, o restante do corpo da mulher sofrerá problemas de saúde para toda a vida. Dessa forma, para essas mulheres, é fundamental que haja uma manutenção do seu bem-estar e de sua saúde.

Também existia o repouso restrito ao leito nos primeiros dias do pós-parto, como expressado pelas mulheres:

Agora ninguém faz resguardo. Três dias em cima da cama minha filha, só se levantava com três dias. Aí depois dos três dias era que eu saía para fora, mas saía pra fora assim ó, dentro de casa. Daqui para "li". Aí com três dias ela mandava a gente arrodear a casa. (Tisha) 
Quando eu cheguei do hospital a minha tia mandou eu ficar só dentro de casa não saia para fora. Daí a minha tia me ensinou arrodear a casa três vezes, que é esse resguardo fino, do tempo da mãe dela e ela ensinou para as sobrinhas. (Malayka)

De primeiro era um resguardo que ave maria. Passava três dias em cima da cama, no quarto dia era que se levantava. (Etana)

\section{Práticas de cuidado relacionadas à higiene}

Nesta subunidade, emergiram os cuidados voltados para a higiene corporal das mulheres no período do pós-parto, especialmente sobre a grande importância da não lavagem dos cabelos, de acordo com as falas a seguir:

A gente só tomava banho com 15 dias... era dito pelos mais velhos e era banho morno... antes a gente só se lavava (Maisha)

De certas partes a gente se lava. Morna a água e se lava, e por derradeiro a gente vai para o rio... é tão bom o banho derradeiro para acabar o resguardo. (Tanisha)

Já o banho eu tomava de água morna. Só que do último o povo do hospital mandou eu tomar banho umas três horas depois que tive menino, e eu era acostumada tomar no outro dia, aí quando cheguei em casa me deu uma dor de cabeça e eu tenho até hoje, por que quebrei o resguardo. (Mariama)

Assim, as mulheres carregam consigo que se não realizarem os cuidados conforme aprendidos, haverá a "quebra do resguardo", levando a problemas de saúde no futuro. Logo, as mulheres mais antigas da comunidade, nos primeiros quinze dias pós-parto, realizavam apenas a higiene da parte íntima e, somente no décimo quinto dia, tomavam banho. Com trinta dias, no término do resguardo, o banho era realizado no rio, local de referência para todas as pessoas da comunidade.

Nota-se que o cuidado com a região íntima almeja, mesmo que empiricamente, a prevenção de infecção puerperal, pois há o risco aumentado para infecção, especialmente nas cirurgias cesarianas e, em menor proporção, nas rafias de laceração do parto.

Aí, nós não "tomava" banho. Agora nós "tinha", sabe, que se lavar. Isso... ainda mais à noite, quando não tinha ninguém. Tudo de água morna... nós "fazia" aquele cozinhado, aquele monte de ervas que elas faziam (Aisha)

Para se lavar a gente colocava um remédio na água, pedra ume, uma pedrinha que nem pedra de sal e barbatimão colocava para cozinhar e lavava a noite, na hora de dormir. (Malayka)

Passava sabão neutro quando ia lavar a cirurgia. Aí enxugava direitinho, secava e depois passava álcool assim na cirurgia. (Chinaka)

As práticas de cuidado relacionadas à higiene da região íntima são universais entre as mulheres quilombolas, pois este é um cuidado que elas realizam durante todo o resguardo. É como se, nesse momento do puerpério, essa região precisasse de mais cuidado do que outra região do corpo, demonstrando que elas estabelecem práticas culturais preventivas.

\section{Práticas de cuidado relacionadas à alimentação}

Ao relatarem sobre a alimentação no pós-parto, as mulheres demonstraram que existem alimentos que podem ser consumidos no puerpério e que serão benéficos para a saúde, como descrito a seguir:

Acho que é por isso que hoje eu tenho saúde, por que eu fazia a dieta. Era um regime medonho. (Etana)

Filha, a comida da gente era pirão de galinha. Quando nós "vinha" comer feijão era depois do banho frio. Quer dizer, feijão de corda, viu? (Amara)

Nós não "come" toda comida, tem a comida escolhida. É a carne de gado, é galinha de capueira, ninguém come galinha de granja. Que hoje em dia é de monte, não come... Bacalhau, charque. Mais outras coisas não! Não! (Tanisha)

Nada carregado para não se prejudicar depois. (Gina)

As mulheres entrevistadas ainda relataram que não consomem, no pós-parto, os alimentos considerados "carregados", devendo ser excluídos da dieta durante esse período.

Não comer nada carregado para não se prejudicar depois. Peixe, fava, negócio de batata, fato de boi, carne de porco. Cada um tinha um tempo para se comer enquanto a mulher estava de dieta (Gina).

No hospital nós "come" feijão. E cá em casa nós não "come", né não?! Agora lá é tudo misturado. Comi banana, queijo que eu não comia... Foi!! Eu dizia: eu não quero não! Eu não sou acostumada a comer não, mas a senhora vai comer, porque a senhora não está em casa. Quando eu cheguei em casa, eu mudei! (Shani)

Nesse sentido, foi possível observar, pelas falas das mulheres, que a alimentação está cercada de crenças, valores e práticas que foram aprendidos e repassados entre as gerações de mulheres da comunidade. 


\section{DISCUSSÃO}

Para que a identidade cultural sobreviva, ela precisa ser perpetuada, uma vez que a transmissão de valores, crenças, normas e estilo de vida garantem o fortalecimento e a resistência de uma determinada cultura. Dentre as transmissões de valores, crenças e práticas é possível observar que a mulher, desde a antiguidade, é a principal cuidadora com funções patriarcais, exercendo a habilidade prática de cuidar ${ }^{7,12}$.

Esse fato de perpetuação de práticas culturais foi visto nessa pesquisa, onde todas as mulheres entrevistadas relataram praticar algum cuidado transmitido por sua mãe, avó, tia ou vizinha. Desse modo, a transmissão das práticas de cuidado e valores, exercidos pelas mulheres quilombolas do Muquém, no pós-parto, confirmam que a cultura local é mantida por meio das gerações.

O período do pós-parto pode ter duração de seis a oito semanas, ou pode ser dividido em puerpério imediato, tardio e remoto ${ }^{4}$, influenciando diretamente no retorno à atividade sexual. No âmbito regional do Muquém, houve uma diversidade cultural relativa a esse tempo de retorno, observando-se uma variação entre trinta a quarenta e cinco dias, havendo a influência dos fatores de parentesco. Já nos estudos de Corrêa e Spindola ${ }^{14,15}$, não se observou um período determinado, mas o momento em que a mulher estava adaptada para retornar.

O conhecimento cultural das mulheres quilombolas são práticas aprendidas como forma de se cuidar para evitar complicações graves no pós-parto, pois estas eram as formas que essas mulheres entendiam que o corpo precisava de repouso para ficar saudável. A fala de Etana, quando remete à "mãe do corpo", está se referindo ao útero e, ao se abster dos afazeres domésticos e das atividades pesadas, ela está auxiliando na recuperação do mesmo e prevenindo doenças; assim ela precisa manter esse cuidado, não podendo transgredir. É possível entender que as mulheres recebem influência das crenças e dos valores das pessoas que as ajudavam nesse período e que, se não realizassem os cuidados conforme eram transmitidos, elas poderiam adoecer e não ficariam mais saudáveis, remetendo-se ao período pré-gravídico, ou seja, haveria a "quebra do resguardo", não existindo uma congruência da universalidade do cuidado cultural ${ }^{16}$.

Para as mulheres do Muquém, esta prática do repouso é universal, pois o cuidado foi repassado por mulheres que já confirmaram sua experiência anterior, visando especialmente evitar as complicações provenientes do pós-parto, como por exemplo a hemorragia. Elas acreditam que as atividades que exigem maior esforço físico poderão aumentar o sangramento, demostrando sua vulnerabilidade.

Sabe-se que a hemorragia pós-parto é uma complicação frequente e uma das principais causas da mortalidade materna. Logo, esse tipo de mortalidade continua sendo um problema em vários países, dentre eles o Brasil, caracterizando um problema de saúde pública ${ }^{17}$.

O puerpério para as mulheres do Muquém é um período de resguardo e de cuidado e que, se não guardado conforme as orientações transmitidas, o corpo pode não retornar ao seu ciclo natural e as complicações podem surgir posteriormente. A cultura dessas mulheres leva elas a crerem que, se no puerpério não existir os devidos cuidados com o corpo, não haverá uma qualidade de vida, pois aparecerão doenças em que elas irão correlacionar ao puerpério não cuidado, ou seja, ao resguardo mal feito, consequentemente levando à "quebra" do mesmo. Num estudo ${ }^{18}$ realizado com mulheres quilombolas num município do Paraná, foi observado que era orientação das parteiras o repouso das mulheres no leito do quarto por três dias com a justificativa de que a mulher não poderia "receber vento frio", pois poderia levá-la a complicações e à morte.

Ao que se refere à prática de não lavagem do cabelo, esta ainda permanece para as mulheres do Muquém, o que nos mostra que esta prática, durante o pós-parto, é um hábito que elas acreditam ser benéfico e que se perpetua até hoje na comunidade, manifestando que a transmissão de crenças e valores caracteriza a função de pertença cultural daquele local.

No estudo de Miranda ${ }^{18}$, a lavagem dos cabelos para as mulheres pesquisadas ainda é preservada, uma vez que para elas lavar a cabeça nos primeiros dias pós-parto pode levar a problemas mentais, cefaleias e hemorragias. Uma das mulheres do estudo que lavou a cabeça antes dos 40 dias, término do resguardo para elas, referiu cefaleia e relacionou à lavagem do cabelo, pois nos resguardos anteriores ela preservou esse cuidado e não apresentou nenhuma comorbidade. O hábito de tomar pelo menos dois banhos ao dia, não sendo citado a restrição para a lavagem ou não da cabeça. Para elas, a higiene era uma forma de hábitos saudáveis e melhora da qualidade de vida.

Durante o período do pós-parto, outro cuidado bastante citado pelas mulheres quilombolas foi relacionado à alimentação. Assim, a depender do grupo, a alimentação envolve diferentes crenças, práticas e significados, os quais são padronizados pela cultura local. Para as mulheres da comunidade quilombola do Muquém, a alimentação não é apenas uma forma de nutrição, mas concebe valores que estão ligados aos cuidados com a saúde ${ }^{18}$.

De acordo com um estudo realizado nas comunidades ribeirinhas, os costumes alimentares apresentam uma série de restrições (tabus), provenientes, em parte, da miscigenação cultural, ou seja, vindos da cultura indígena, negra e de 
colonizadores portugueses. Dessa forma, as mulheres ficam sujeitas a influências em relação às restrições alimentares nesse período, já que consideram que alguns alimentos dificultam o processo de recuperação da saúde ${ }^{19}$. As concepções das mulheres quilombolas sobre os alimentos "carregados" se mostram como uma singularidade na forma de cuidar, que é envolta por crenças, valores e práticas, os quais são verdadeiras e corretas formas de cuidado. Assim, o modo de vida e a visão de mundo dessas mulheres apresenta relação direta com o seu contexto cultural local. Sob o olhar da teórica Leininger, observa-se que a alimentação possui valores culturais que estão ligados ao cuidado à saúde, uma vez que para as mulheres quilombolas os alimentos podem ser considerados saudáveis ou prejudicais, sendo a prática da alimentação uma semelhança entre as mulheres do Muquém, ao passo que buscam reproduzir as particularidades dos seus valores culturais e modos de vida, conservando a identidade e sustentando o cuidado cultural local ${ }^{12}$.

\section{CONSIDERAÇÕES FINAIS}

As práticas de cuidado desenvolvidas por mulheres quilombolas no pós-parto se caracterizam por receber influência das crenças, valores e modos de vida que foram repassados, por meio da oralidade, por outras mulheres que já tinham vivenciado esse período. Assim, os cuidados executados no puerpério por mulheres do Muquém são realizados na perspectiva de garantia de saúde para o resto da vida, uma vez que elas acreditam que, se a "mãe do corpo" está bem, todo o organismo feminino irá retornar para seu estado pré-gestacional sem complicações.

Desse modo, é de fundamental importância que os profissionais de saúde que assistem as puérperas conheçam o modo de vida, as crenças e os valores nelas enraizados, para que prestem um cuidado culturalmente congruente, pois o puerpério vai além da dimensão fisiológica, abrangendo a dimensão sociocultural, sofrendo influência, especialmente, dos fatores de parentesco.

\section{REFERÊNCIAS}

1. Castiglioni CM, Wilhelm LA, Prates LA et al. Self-care practices: women in the puerperal period. Rev. enferm. UFPE online, 2016 [cited 2020 Feb 15]; 10(10): 3751-9. Available from: https://periodicos.ufpe.br/revistas/revistaenfermagem/article/view/11440

2. Silva SGF, Condeles PC, Parreira BM, Silva SR, Paschoini MC, Ruiz MT. Influence of sociodemographic, clinical, obstetric and neonatal variables on postpartum quality of life. Rev. enferm. UERJ [Internet], 2019 [cited 2020 Feb 15]; 27: e44636. DOI: https://doi.org/10.12957/reuerj.2019.44636

3. Quirino AFA, Ferrari RAP, Maciel SM, Santos IDL, Medeiros FF, Cardelli AAM. Self-care practices in the first year postpartum. Cienc. Cuid. Saude. 2016 [cited 2020 Feb 15]; 15(3): 436-44. DOI: https://doi.org/10.4025/cienccuidsaude.v15i3.31787

4. Andrade RD, Santos JS, Maia MAC, Melo DF. Factors related to women's health in puerperium and repercussions on child health. Esc. Anna Nery. 2015 [cited 2020 Feb 15]; 19(1): 181-86. Available from: https://www.scielo.br/scielo.php?pid=S1414$81452015000100181 \&$ script $=$ sci_abstract\&tlng=en

5. Melo RM, Angelo BHB, Pontes CM, Brito RS. Men's knowledge of labor and childbirth. Esc. Anna Nery. 2015 [cited 2020 Feb 15]; 19(3): 454-59. Available from: https://www.scielo.br/scielo.php?pid=S1414-81452015000300454\&script=sci_arttext\&tlng=en

6. Teixeira E, Martins TDM, Miranda PO, Cabral BG. Educational technology on potpartum care: development and validation. Revista Baiana de Enfermagem. 2016 [cited 2020 Jun 20]; 30 (2), 1-10. DOI: https://doi.org/10.18471/rbe.v30i2.15358

7. Leininger MM, Mcfarland MR. Cultural care diversity and universatily: a worldwide nursing theory. New York; Jones \& Bartlett Learning: $3^{\text {rd }}$ ed., 2014.

8. Bezerra VM, Medeiros DS, Gomes KO, Souzas R, Giatti L, Steffens AP, Kochergin CN, Souza CL, Moura CS, Soares DA, Santos LRCS, Cardoso LGV, Martins PC, Neves OSC, Guimarães MDC. Health survey in Quilombola communities (descendants of AfroBrazilian slaves who escaped from slave plantations that existed in Brazil until abolition in 1888) in Vitória da Conquista in the state of Bahia (Conquista Project), Brazil: methodological aspects and descriptive analysis. Ciênc. Saúde Coletiva [online]. 2014 [cited 2019 Feb 15]; 19(6): 1835-47. DOI: https://doi.org/10.1590/1413-81232014196.01992013

9. Pereira LL, Silva HP, Santos LMP. More doctors for Brazil project: a case study in quilombo communities. Rev. Associação Bras. Pesquisadores Negros. 2015 [cited 2020 Jun 20]; 7(16):28-51. Available from: https://www.researchgate.net/publication/281032212

10. Silveira DB, Chagas MDF, Hora TS et al. Implications of culture for care by a family health team in a quilombola community. Rev. enferm. UERJ. 2015 [cited 2019 Feb 15]; 23(5): 622-6. DOI: https://dx.doi.org/10.12957/reuerj.2015.17734

11. Siqueira LKR, Melo MCP, Morais RJL. Postpartum and sexuality: maternal perspectives and adjustments. Rev. Enferm. UFSM REUFSM. 2019 [cited 2010 Jun 20]; 9:e58,1-18. DOI: https://periodicos.ufsm.br/reufsm/article/view/33495/html_1

12. Leininger MM, Mcfarland MR. Transcultural nursing: concepts, theories, reseach and practice. Columbus: McGraw-Hill Education / Medical; Edição: 4, 2018.

13. Collière MF. Cuidar a primeira arte da vida. Lusociência: Paris; 2001.

14. Corrêa MSM, Feliciano KVO, Pedrosa EM, Souza AI. Acolhimento no cuidado à saúde da mulher no puerpério. Cad. Saúde Pública. 2017 [cited 2020 Feb 15]; 33(3):e00136215. DOI: https://doi.org/10.1590/0102-311x00136215

15. Spindola T, Penha LH, Lapa AT, Cavalcante ALS, Silva JMR, Santana RSC. The postpartum period from the perspective of women attended at a university hospital. Enferm. Foco. 2017 [cited 2020 Feb 15]; 8(1): 42-6. DOI: https://doi.org/10.21675/2357707X.2017.v8.n1.847 
16. Ruiz MT, Paraiso NA, Machado ARM, Ferreira MBG et al. Blood loss and signs or symptoms during puerperal assessment: implications for nursing care. Rev. enferm. UERJ. 2017 [cited 2020 Feb 15]; 25: e22756. DOI: https://dx.doi.org/10.12957/reuerj.2017.22756

17. Muniz JC, Silva LE. "Mais que isso eu não posso falá": notas sobre benzeduras e parteiragens Caiçara em Guaraqueçaba/PR. Revista Brasileira de Geografia Médica e da Saúde. 2016 [cited 2019 Feb 15]; 12(23):31-43. Available from: http://www.seer.ufu.br/index.php/hygeia/article/view/33704

18. Miranda DB, Marostica FC, Matão MEL. Influência do fator cultural no processo de cuidado puerperal. Revista Eletrônica Gestão \& Saúde. 2015 [cited 2020 Feb 15]; 6(3): 2444-59. Available from: https://dialnet.unirioja.es/descarga/articulo/5555805.pdf

19. Lopes TMR, Brito ACM, Corrêa CP, Rocha DSA, et al. Nursing, food "reimosos" and the cross-cultural service to the Amazonian riverside population: an experience report. Revista Eletrônica Acervo Científico, 2019 [cited 2020 Jun 18] 4:e349. DOI: https://doi.org/10.25248/reac.e349.2019 